\title{
Bradykinin Type 1 Receptor - Inducible Nitric Oxide Synthase: A New Axis Implicated in Diabetic Retinopathy
}

\author{
Rahmeh Othman ${ }^{1,2}$, Elvire Vaucher ${ }^{1}$ and Réjean Couture ${ }^{2 *}$ \\ 'School of Optometry, University of Montreal, Montreal, QC, Canada, ${ }^{2}$ Department of Pharmacology and Physiology, \\ University of Montreal, Montreal, QC, Canada
}

\section{OPEN ACCESS}

Edited by:

Stefania Tacconelli, Università degli Studi G. d'Annunzio

Chieti e Pescara, Italy

Reviewed by:

Tapas C. Nag,

All India Institute of Medical Sciences,

India

Federica Finetti,

University of Siena, Italy

*Correspondence:

Réjean Couture

rejean.couture@umontreal.ca

Specialty section:

This article was submitted to Inflammation Pharmacology,

a section of the journal

Frontiers in Pharmacology

Received: 19 December 2018

Accepted: 11 March 2019

Published: 29 March 2019

Citation:

Othman R, Vaucher E and Couture R (2019) Bradykinin Type 1 Receptor - Inducible Nitric Oxide Synthase: A New Axis Implicated in

Diabetic Retinopathy.

Front. Pharmacol. 10:300. doi: 10.3389/fphar.2019.00300
Compelling evidence suggests a role for the inducible nitric oxide synthase, iNOS, and the bradykinin type 1 receptor (B1R) in diabetic retinopathy, including a possible control of the expression and activity of iNOS by B1R. In diabetic retina, both iNOS and B1R contribute to inflammation, oxidative stress, and vascular dysfunction. The present study investigated whether inhibition of iNOS has any impact on inflammatory/oxidative stress markers and on the B1R-iNOS expression, distribution, and action in a model of type I diabetes. Diabetes was induced in 6-week-old Wistar rats by streptozotocin (65 mg. $\mathrm{kg}^{-1}$, i.p.). The selective iNOS inhibitor 1400W (150 $\mu \mathrm{g} .10 \mu \mathrm{l}^{-1}$ ) was administered twice a day by eye-drops during the second week of diabetes. The retinae were collected 2 weeks after diabetes induction to assess the protein and gene expression of markers by Western blot and qRT-PCR, the distribution of iNOS and B1R by fluorescence immunocytochemistry, and the vascular permeability by the Evans Blue dye technique. Diabetic retinae showed enhanced expression of iNOS, $B 1 R$, carboxypeptidase M (involved in the biosynthesis of B1R agonists), IL-1 $\beta, T N F-\alpha$, vascular endothelium growth factor A (VEGF-A) and its receptor, VEGF-R2, nitrosylated proteins and increased vascular permeability. All those changes were reversed by treatment with $1400 \mathrm{~W}$. Moreover, the additional increase in vascular permeability in diabetic retina induced by intravitreal injection of R-838, a B1R agonist, was also prevented by $1400 \mathrm{~W}$. Immunofluorescence staining highlighted strong colocalization of iNOS and B1R in several layers of the diabetic retina, which was prevented by $1400 \mathrm{~W}$. This study suggests a critical role for iNOS and B1R in the early stage of diabetic retinopathy. B1R and iNOS appear to partake in a mutual auto-induction and amplification loop to enhance nitrogen species formation and inflammation in diabetic retina. Hence, B1R-iNOS axis deserves closer scrutiny in targeting diabetic retinopathy.

Keywords: diabetic retinopathy, bradykinin type 1 receptor, inducible nitric oxide synthase, kallikrein-kinin system, inflammation, oxidative stress

Abbreviations: 1400W, N-[3-(aminomethyl)benzyl]acetamidine; BK, bradykinin; B1R, bradykinin type 1 receptor; B2R, bradykinin type 2 receptor; CRL, Cones and rods layer; CPM, carboxypeptidase M; DR, diabetic retinopathy; GCL, ganglion cell layer; IL-1 $\beta$, interleukin-1 $\beta$; INL, inner nuclear layer; iNOS, inducible nitric oxide synthase; IPL, inner plexiform layer; KD, kallidin; NO, nitric oxide; ONL, outer nuclear layer; OPL, outer plexiform layer; RPE, retinal pigmented epithelium; R-838, Sar-[D-Phe ${ }^{8}$-des-Arg ${ }^{9}$-BK; STZ, streptozotocin; TNF- $\alpha$, tumor necrosis factor- $\alpha$; VEGF-A, vascular endothelial growth factor; VEGF-R2, receptor type 2 of VEGF. 


\section{INTRODUCTION}

DR is a major complication of diabetes mellitus and the leading cause of blindness in working-age adults (Fong et al., 2004). Most patients with type I diabetes develop retinopathy in the first two decades of the disease (Fong et al., 2004). In its early stage, DR is asymptomatic even though the development of vascular bed damage involving changes in retinal vessel diameter, alterations in retinal hemodynamics, increase in leakage of the blood-retinal barrier, overexpression, and accumulation of vascular endothelial growth factor, VEGF (Cheung et al., 2010). This vascular damage progresses into retinal hemorrhage, hard exudates and the appearance of microaneurysms.

Current therapeutic interventions are used only for the late stage of DR when microvascular complications have already resulted in irreversible structural changes. These treatments, including the intravitreal injections of anti-VEGF and laser photocoagulation, are invasive, need to be repeated regularly and are only able to stop the progression of DR without restoring the loss of vision (Fong et al., 2004). Therefore, more effective treatments are needed to intervene in an early stage of DR. Many studies have shown an implication of several pro-inflammatory and oxidative stress mediators in the early stage of this ocular disease (Bhat et al., 2014). Among them, the inducible isoform of NO synthase (iNOS) is overexpressed and activated in ischemic and diabetic rodent retinae (Carmo et al., 2000; Sennlaub et al., 2001, 2002; Ellis et al., 2002; Yuasa et al., 2008; Rosales et al., 2010; Silva et al., 2010) and in diabetic human retina (Abu El-Asrar et al., 2001, 2004). $\mathrm{NO}$ is a potent vasodilatory gas and is considered as a free radical due to the presence of an unpaired electron in its valence shell. Being highly reactive, especially with the superoxide anions, NO largely contributes to the oxidative stress, inducing retinal cells damage. Thus, compelling evidence suggests that iNOS is implicated in the onset of DR (Zheng et al., 2007; Mishra and Newman, 2010).

Under physiological situation, NO produced at low amounts by the constitutive isoforms of NOS, endothelial NOS (eNOS) and neuronal NOS (nNOS), plays, however, an important role in ocular hemodynamics and cell viability (Toda and NakanishiToda, 2007), being involved in vasodilation, neurotransmission and host cell defense (Christopherson and Bredt, 1997). However, NO produced at high concentrations by iNOS, leads to tissue injury, neurodegeneration, cell apoptosis (Christopherson and Bredt, 1997; Toda and Nakanishi-Toda, 2007), and inflammatory responses (Korhonen et al., 2005; Ricciardolo et al., 2006). Moreover, excess of NO can lead to the formation of peroxynitrite (Goureau et al., 1999; Ellis et al., 2002; Rosales et al., 2010; Hao et al., 2012), which is associated with DR and degenerative diseases.

Earlier studies have shown that the iNOS inhibitor, aminoguanidine, inhibited NO production, protein nitration, iNOS expression, vascular dysfunction, and retinal cell death in diabetic rats (Corbett et al., 1992; Du et al., 2002, 2004). Aminoguanidine also prevented the development of microvascular lesions (retinal microaneurysms, acellular capillaries, and pericyte ghosts) in type 1 diabetic dogs over a period of 5 years (Kern and Engerman, 2001). In streptozotocin (STZ)-induced diabetes in Long-Evans rats, aminoguanidine and 1400W (a more selective and potent iNOS inhibitor) restored light- and glial-evoked vasodilation in the retina, suggesting a role for iNOS in the loss of functional hyperemia due to aberrant glia-to-vessel signaling (Mishra and Newman, 2010). In a mouse model of oxygen-induced retinopathy, genetic deletion of iNOS or its blockade with 1400W increased physiological neovascularization and blunted the pathological intravitreal neovascularization (Sennlaub et al., 2001). In the same murine model, authors showed that iNOS is implicated in retinal degeneration through apoptosis (Sennlaub et al., 2002).

The kallikrein-kinin system is also involved in the development of DR (Wilkinson-Berka and Fletcher, 2004; Feener, 2010; Bhat et al., 2014). BK and KD are the agonists of the constitutive $\mathrm{B} 2$ receptor (B2R) while their metabolites produced by the CPM (Des-Arg ${ }^{9}-\mathrm{BK}$ and Des-Arg ${ }^{10}-\mathrm{KD}$ ) are the preferred agonists of the inducible B1 receptor (B1R) (Regoli and Barabe, 1980; Regoli et al., 1998). Kinin receptors play an important role in the regulation of local blood flow, tissue edema, vasodilation, and leukocytes infiltration (Couture et al., 2001). B2R plays a vasodilator and vasoprotector role through activation of eNOS and prostanoids. B1R is undetectable in physiological conditions; it is induced in pathological conditions by proinflammatory cytokines and by oxidative stress associated with hyperglycemia (Leeb-Lundberg et al., 2005; Couture et al., 2014). The inducible $\mathrm{B} 1 \mathrm{R}$ is implicated in complications of type 1 and type 2 diabetes (Couture et al., 2014), notably in DR. B1R was upregulated by an oxidative stress mechanism in the retina of STZ-diabetic rats (Abdouh et al., 2003, 2008; Pouliot et al., 2012) and its ocular blockade prevented the development of the pathogenesis of DR (Pouliot et al., 2012; Hachana et al., 2018). It was also shown that B1R is associated with the oxidative stress in the optic nerve and cortical visual area of 1 and 4 weeks STZ-diabetic rats (Catanzaro et al., 2017). It is worth noting that B1R activates iNOS through Gai/ERK/MAPK signaling pathways in HEK293 cells (Brovkovych et al., 2011) and B1R antagonism reverses iNOS overexpression in the retina and pancreas of STZ-diabetic rats (Pouliot et al., 2012; Tidjane et al., 2016). These studies suggested that B1R is located upstream to iNOS activation and expression in diabetes.

To better understand the B1R-iNOS relationship in DR, we investigated the expression and distribution of B1R and iNOS in 2 weeks STZ-diabetic retinae to enable comparison with previous studies using B1R antagonists (Pouliot et al., 2012; Hachana et al., 2018). The impact of the iNOS inhibitor $1400 \mathrm{~W}$ was determined on the expression of inflammatory mediators, notably iNOS, kallikrein-kinin system molecules, including carboxypeptidase $\mathrm{M}$ (CPM) which controls the activation of $\mathrm{B} 1 \mathrm{R}$, and VEGF which is involved in many aspects of vascular damage (Hoeben et al., 2004). The effect of 1400W on diabetesinduced nitrosative stress and retinal vascular permeability and on vascular hyperpermeability induced by a B1R agonist was also evaluated. This study highlights a partnership between $\mathrm{B} 1 \mathrm{R}$ and iNOS in DR. 


\section{MATERIALS AND METHODS}

\section{Model of STZ-Diabetic Rat}

All experimental methods and animal care procedures were approved by the animal care committee of the Universite de Montréal (Protocols 15-063, 16-059, and 17-057), in accordance with the Canadian Council on Animal Care. Animal studies are reported in compliance with the ARRIVE guidelines (Kilkenny et al., 2010; McGrath and Lilley, 2015). Six-week-old male Wistar rats weighing between 200 and $225 \mathrm{~g}$ were purchased from Charles River Laboratories (St-Constant, QC, Canada) and housed two per cage in a room under standard conditions $\left(22.5^{\circ} \mathrm{C}\right.$ and $42.5 \%$ humidity, on a $12 \mathrm{~h} / 12 \mathrm{~h}$ light-dark cycle), with a standard chow diet (Charles River Rodent) and water provided ad libitum. Diabetes was induced by a single intraperitoneal injection of Streptozotocin (STZ, Zanosar 65 mg.kg-1 Cayman Chemical, Ann Arbor, MI, United States). Age-matched control rats were injected with vehicle used to solubilize STZ; 0.1M citrate buffer $\mathrm{pH} 5$.

Glucose concentrations and body weight were recorded every 3 days and on the day of the experiments. Diabetes was confirmed by the measurement of a blood glucose concentration greater than $20 \mathrm{mmol} . \mathrm{L}^{-1}$ with a commercial blood glucose analyzer (Accusoft; Roche Diagnostics, Laval, QC, Canada) (Pouliot et al., 2012).

\section{Topical Ocular Treatment With the iNOS Selective Inhibitor 1400W}

One week after diabetes induction, rats were treated twice a day (8 AM and $5 \mathrm{PM}$ ) with one eye drop application of the selective iNOS inhibitor $1400 \mathrm{~W}$ for a 7 -day period. N-(3-(aminomethyl) benzyl)acetamidine (1400W, Cayman Chemical, Ann Arbor, United States) is an extremely slowly reversible inhibitor for human and rat iNOS with a 5000-fold selectivity for iNOS versus eNOS and nNOS (Garvey et al., 1997). In a previous study, we reported that $1400 \mathrm{~W}$ can prevent the deleterious effects of B1R in insulin resistance and peripheral inflammation by blocking the formation of peroxynitrite (Haddad and Couture, 2016). In a model of ischemic retinopathy, 1400W also inhibited the pathological neovascularization (Sennlaub et al., 2001, 2002). For our study, fresh solution $\left(15 \mathrm{mg} \cdot \mathrm{mL}^{-1}\right)$ was prepared daily with sterile saline $0.9 \%$ and filtrated $(0.20 \mu \mathrm{m}$ mesh). This dosage was chosen based on a pilot dose-response study where $10 \mu \mathrm{L}$ of $5 \mathrm{mg} \cdot \mathrm{mL}^{-1}$ failed to affect the increase of vascular permeability in STZ-retina. The latter inflammatory response was slightly decreased with $10 \mu \mathrm{L}$ of $10 \mathrm{mg} \cdot \mathrm{mL}^{-1}$, and completely reversed with $10 \mu \mathrm{L}$ of $15 \mathrm{mg} \cdot \mathrm{mL}^{-1}$. In the present study, $10 \mu \mathrm{L}$ of the $15 \mathrm{mg} . \mathrm{mL}^{-1}$ solution (i.e., $150 \mu \mathrm{g}$ in $10 \mu \mathrm{l}$ ) was administered twice a day on the surface of the eye using a pipette. To make sure that the drop effectively remained on the surface of the eye, animals were hand-restrained for $60 \mathrm{~s}$. The presence of ocular irritation such as redness, porphyrin secretion or corneal opacity was verified daily.

\section{Intravitreal Injection of the B1R Agonist R-838}

To assess the contribution of iNOS in B1R-induced vascular permeability, twenty rats were randomly divided into two control groups and two STZ-diabetic groups of 5 rats per group. Control groups and STZ-diabetic groups were treated either with the vehicle or with $1400 \mathrm{~W}$ by eye-drops. Pupils of isoflurane anesthetized rats were dilated with $0.5 \%$ tropicamide to allow intravitreal injections on day 10 and 12. Under a dissecting microscope, a small incision of $1 \mathrm{~mm}$ was done behind the limbus using a 30-gauge needle to facilitate the intravitreal injections. A sterile solution of the B1R agonist R-838 synthesized at the Research Institute of Biotechnology, National Research Council of Canada (Montreal, QC, Canada) (100 ng in $5 \mu \mathrm{L}$ of $0.9 \%$ saline) was injected into the vitreous through the incision using a glass micropipette sealed at the tip of the Hamilton microsyringe $(10 \mu \mathrm{L})$ (Hamilton, Reno, NV, United States) according to

TABLE 1 | List of primers designed by vector NTI software and used in qRT-PCR analysis.

\begin{tabular}{|c|c|c|c|c|c|c|}
\hline \multirow{2}{*}{$\frac{\text { Gene }}{B 1 R}$} & \multirow[b]{2}{*}{ Forward } & \multicolumn{3}{|c|}{ Sequence } & \multirow{2}{*}{$\begin{array}{l}\text { Position } \\
367-390\end{array}$} & \multirow{2}{*}{$\frac{\text { GenBank accession no }}{\text { NM_030851 }}$} \\
\hline & & $5^{\prime}$ & GCAGCGCTTAACCATAGCGGAAAT & $3^{\prime}$ & & \\
\hline & Reverse & $5^{\prime}$ & CCAGTTGAAACGGTTCCCGATGTT & $3^{\prime}$ & $454-431$ & \\
\hline \multirow[t]{2}{*}{$\mathrm{B} 2 \mathrm{R}$} & Forward & $5^{\prime}$ & AGGTGCTGAGGAACAACGAGATGA & $3^{\prime}$ & 882-905 & NM_173100 \\
\hline & Reverse & $5^{\prime}$ & TCCAGGAAGGTGCTGATCTGGAAA & $3^{\prime}$ & $990-967$ & \\
\hline \multirow[t]{2}{*}{ iNOS } & Forward & $5^{\prime}$ & TGATCTTGTGCTGGAGGTGACCAT & $3^{\prime}$ & $1150-1173$ & NM_012611 \\
\hline & Reverse & $5^{\prime}$ & TGTAGCGCTGTGTGTCACAGAAGT & $3^{\prime}$ & $1349-1326$ & \\
\hline \multirow[t]{2}{*}{ VEGF-A } & Forward & $5^{\prime}$ & TCACCAAAGCCAGCACATAGGAGA & $3^{\prime}$ & $1219-1242$ & BC168708 \\
\hline & Reverse & $5^{\prime}$ & TTACACGTCTGCGGATCTTGGACA & $3^{\prime}$ & $1371-1348$ & \\
\hline \multirow[t]{2}{*}{ VEGF-R2 } & Forward & $5^{\prime}$ & AGTGGCTAAGGGCATGGAGTTCTT & $3^{\prime}$ & 3269-3292 & U93306 \\
\hline & Reverse & $5^{\prime}$ & GGGCCAAGCCAAAGTCACAGATाT & $3^{\prime}$ & $3387-3364$ & \\
\hline \multirow[t]{2}{*}{$\| \mathrm{L}-1 \beta$} & Forward & $5^{\prime}$ & TGTCACTCATTGTGGCTGTGGAGA & $3^{\prime}$ & $247-270$ & NM_031512 \\
\hline & Reverse & $5^{\prime}$ & TGGGAACATCACACACTAGCAGGT & $3^{\prime}$ & $411-388$ & \\
\hline \multirow[t]{2}{*}{ TNF- $\alpha$} & Forward & $5^{\prime}$ & ACGGAAAGCATGATCCGAGATGTG & $3^{\prime}$ & $151-174$ & NM_012675 \\
\hline & Reverse & $5^{\prime}$ & TTGGGAACTTCTCCTCCTTGTTGG & $3^{\prime}$ & $340-317$ & \\
\hline \multirow[t]{2}{*}{$18 S$} & Forward & $5^{\prime}$ & TCAACTITCGATGGTAGTCGCCGT & $3^{\prime}$ & 363-386 & X01117 \\
\hline & Reverse & $5^{\prime}$ & TCCTTGGATGTGGTAGCCGTTCT & $3^{\prime}$ & $470-447$ & \\
\hline
\end{tabular}


TABLE 2 | Effects of diabetes, B1R agonist (R-838) and iNOS inhibitor (1400W) on body weight and glycaemia.

\begin{tabular}{lcc}
\hline Groups & $\begin{array}{c}\text { Body } \\
\text { weight (g) }\end{array}$ & $\begin{array}{c}\text { Glycaemia } \\
\text { (mmol.L-1) }\end{array}$ \\
\hline Control $(n=12)$ & $382 \pm 5$ & $5.0 \pm 0.1$ \\
Control + R-838/vehicle $(n=5)$ & $373 \pm 7$ & $5.1 \pm 0.1$ \\
Control + R-838/vehicle + 1400W $(n=5)$ & $379 \pm 9$ & $5.2 \pm 0.1$ \\
STZ $(n=12)$ & $314 \pm 9^{*}$ & $27.8 \pm 0.7^{*}$ \\
STZ + 1400W $(n=12)$ & $300 \pm 10^{*}$ & $27.7 \pm 0.7^{*}$ \\
STZ + R-838/vehicle $(n=5)$ & $291 \pm 6^{*}$ & $29.2 \pm 1.2^{*}$ \\
STZ + R-838/vehicle $+1400 \mathrm{~W}(n=5)$ & $292 \pm 7^{*}$ & $28.8 \pm 0.9^{*}$ \\
\hline
\end{tabular}

Values represent the mean \pm S.E.M of five to twelve rats per group (as indicated by n). R-838 was administered in one eye and the effect compared to the opposite eye treated with the vehicle. Statistical significance was determined with oneway ANOVA followed by the Tukey Test. ${ }^{*} P<0.05$ significantly different from the corresponding control. STZ, streptozotocin-treated rats.

our previous study (Hachana et al., 2018). The contralateral eye received intravitreal injection of the vehicle (saline) for comparison. Retina samples were collected at day 15 to measure the vascular permeability using the Evans blue dye technique.

\section{Measurement of Retinal Vascular Permeability}

Retinal vascular permeability was measured using Evans blue dye extravasation technique as previously described (Abdouh et al., 2008; Pouliot et al., 2012). Rats underwent general anesthesia by intraperitoneal injection of sodium pentobarbital $\left(60 \mathrm{mg} \cdot \mathrm{kg}^{-1}\right)$. A catheter (Micro-Renathane, I.D. 0.040", O.D. 0.020", Braintree Scientific, Braintree, MA, United States) was inserted into the right femoral vein and Evans blue dye (45 mg. $\mathrm{mL}^{-1}$ in $0.9 \%$ saline) (Sigma-Aldrich, Oakville, ON, Canada) was injected i.v. over $10 \mathrm{~s}$. The rats were kept on a heating pad for $2 \mathrm{~h}$ to allow the dye to circulate, while the body temperature was monitored at every $10 \mathrm{~min}$. Thereafter, the rats were infused with a $25 \mathrm{~mL}$ of sterile saline $0.9 \%$ through the left heart ventricle, to wash out intravascular dye. Both eyes were then enucleated, and the retinae were dissected out and immediately weighed.
Evans blue dye was extracted by incubating each retina in $1 \mathrm{~mL}$ formamide (Sigma-Aldrich, Oakville, ON, Canada) for $18 \mathrm{~h}$ at $70-75^{\circ} \mathrm{C}$. The fluorescence of Evans blue was measured using a spectrofluorometer (Spex 16810.22 m, Horiba JobinYvon Inc, Edison, NJ, United States) at $620 \mathrm{~nm}$ (excitation) and $680 \mathrm{~nm}$ (emission). Based on a standard curve, data were calculated in $\mu \mathrm{g}$ of Evans blue and then expressed per $g$ of fresh tissue.

\section{Measurement of Retinal Inflammatory Mediators by Quantitative RT-PCR}

As previously described (Pouliot et al., 2012), rats were anesthetized with sodium pentobarbital $\left(60 \mathrm{mg} \cdot \mathrm{kg}^{-1}\right.$, i.p.) and the retinae were dissected out and put in RNAlater stabilization reagent (QIAGEN, Valencia, CA, United States). Total RNA was extracted from retinae using a commercial kit (QIAGEN, Valencia, CA, United States). First-strand cDNA synthesized from $400 \mathrm{ng}$ total RNA with random hexamer primers was used as template for each reaction with the QuantiTect Rev Transcription Kit (QIAGEN). SYBR Green-based real-time quantitative PCR using Mx3000p device for signal detection (Stratagene, La Jolla, CA, United States) was performed as previously described (Abdouh et al., 2008; Pouliot et al., 2012). PCR was performed in SYBR Green Master mix (QIAGEN) with $300 \mathrm{nM}$ of each primer. The primer pairs designed by Vector NTI software are shown in Table 1. For standardization and quantification, rat $18 \mathrm{~S}$ was amplified simultaneously. PCR conditions were as follows: $95^{\circ} \mathrm{C}$ for $15 \mathrm{~min}$, followed by 46 cycles at $94^{\circ} \mathrm{C}$ for $15 \mathrm{~s}, 60^{\circ} \mathrm{C}$ for $30 \mathrm{~s}$, and $72^{\circ} \mathrm{C}$ for $30 \mathrm{~s}$. The cycle threshold $(\mathrm{Ct})$ value represents the cycle number at which a fluorescent signal rises statistically above background. The relative quantification of gene expression was analyzed by the $2^{-\Delta \Delta \mathrm{Ct}}$ method.

\section{Measurement of Retinal Inflammatory Mediators by Western Blot}

The measurement of protein expression of retinal inflammatory mediators was done using the Western Blot technique as previously described (Pouliot et al., 2011; Haddad and Couture, 2016). $40 \mu \mathrm{g}$ of protein were loaded in each well of $10 \%$ SDS-PAGE and separated electrophoretically at $100 \mathrm{~V}$ for
A
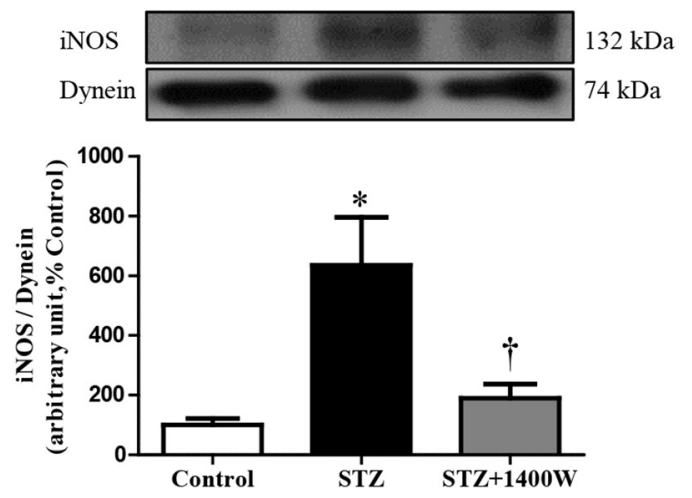

B

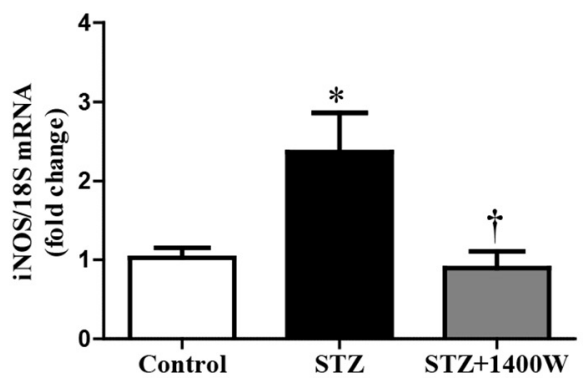

FIGURE 1 | Effect of STZ-induced diabetes and eye-drops 1400W treatment on protein (A) and mRNA (B) expression of iNOS in the retina. Data are mean \pm SEM of values obtained from five rats in each group. ${ }^{*} P<0.05$ STZ-diabetic compared with control; ${ }^{\dagger} P<0.05$ STZ $+1400 \mathrm{~W}$ compared with STZ. 
$125 \mathrm{~min}$. Proteins were then transferred onto a nitrocellulose membrane (Bio-Rad, Montreal, QC, Canada) at $100 \mathrm{~V}$ for 1 h. After 3 sets of 5 min washing in phosphate-buffered saline (PBS), the membranes were incubated in a blocking solution with PBS-Tween 20 containing 5\% of dehydrated skimmed milk at $4^{\circ} \mathrm{C}$ for $1 \mathrm{~h}$. The membranes were then incubated with specific primary antibody in 5\% skimmed milk overnight at $4^{\circ} \mathrm{C}$. Dynein and $\beta$-actin were used as standard proteins. The membranes were washed again $3 \times 10$ min with PBS-Tween 20. The antibody-antigen complexes were detected by adding secondary antibody in $1 \%$ skimmed milk at room temperature for $1 \mathrm{~h}$ and protein bands were visualized by enhanced chemiluminescence improved for the western blot (Super-Signal ${ }^{\circledR}$; Thermo Scientific, Rockford, IL, United States). Quantitative analysis of specific bands was performed by densitometry using the MCID-M1 system (Imaging Research, St. Catharines, ON, Canada).

As described previously (Haddad and Couture, 2016), the detection of $\mathrm{BK}$ receptor proteins was made with selective polyclonal rabbit antiserum for B1R (1:1000), and B2R (1:1000) (Biotechnology Research Institute, Montreal, QC, Canada). Specificity of both antisera was determined in B1 and B2
A
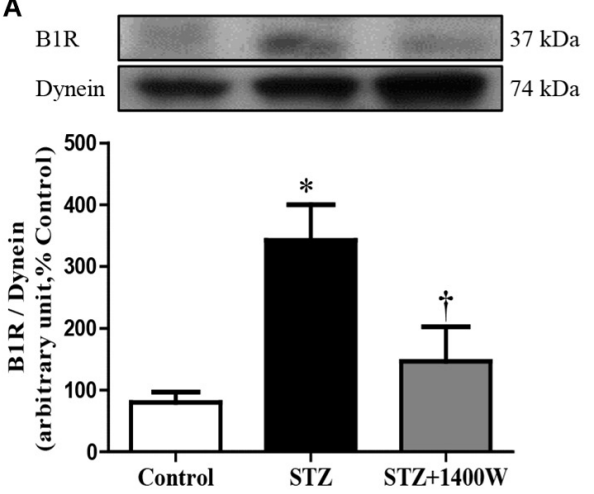

C
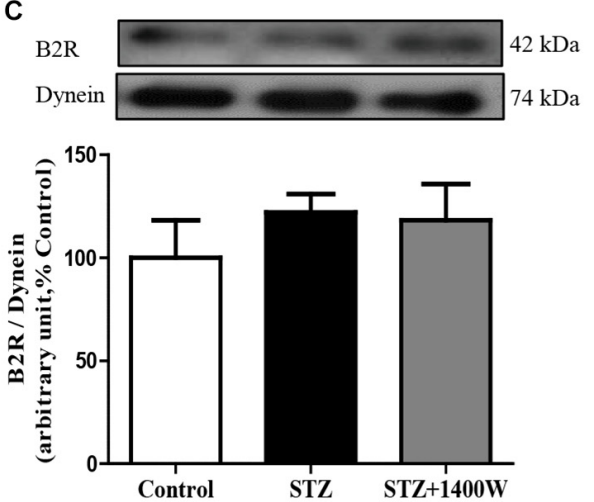

E
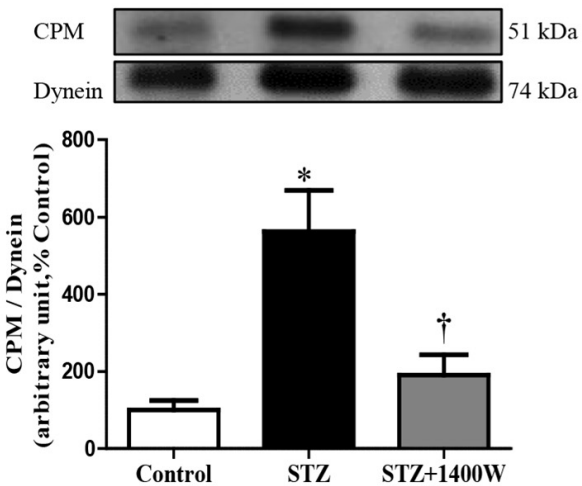

B

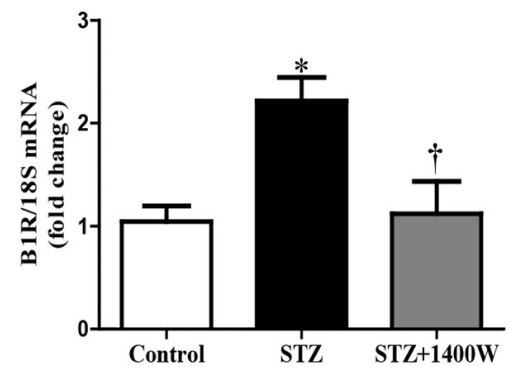

D

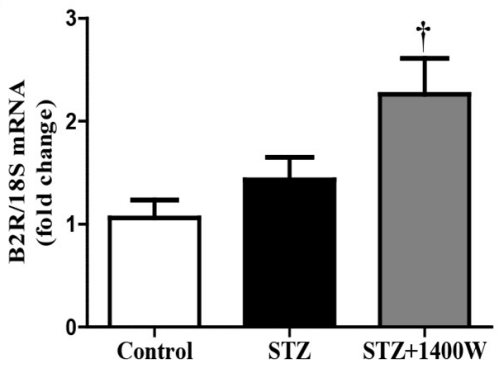

FIGURE 2 | Effect of STZ-induced diabetes and eye-drops 1400W treatment on the expression of kinin B1R (A,B), B2R (C,D), and CPM (E) at protein (A,C,E) and mRNA (B,D) levels in the retina. Data are mean \pm SEM of values obtained from five rats per group or six rats in CPM group. ${ }^{*} P<0.05$ STZ-diabetic compared with control; ${ }^{\dagger} P<0.05 \mathrm{STZ}+1400 \mathrm{~W}$ compared with STZ. 
receptor knockout (KO) mice and by siRNA technology (Dias et al., 2010; Lacoste et al., 2013; Hachana et al., 2018). The other primary antibodies were as follows: iNOS (NOS2) (1:1500, rabbit, SC-650), IL-1 $\beta$ (1:500, rabbit, SC-7884), CPM (1:500, rabbit, SC-98698), dynein (1:5000, mouse, SC-13524), $\beta$-actin (1:5000, mouse, SC-47778), (SC: Santa Cruz Biotechnology, CA, United States), nitrotyrosine (1:1500 mouse, 1A6-05233;

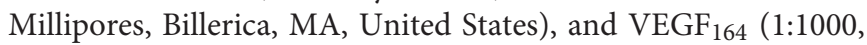
goat, AF564; R\&D systems, Minneapolis, MN, United States). Secondary antibodies were horseradish peroxidase (HRP)-linked with: goat anti-mouse (SC-2005) or goat anti-rabbit (SC-2004) or donkey anti-goat (SC-2020) and HRP-linked used at dilution of 1:25000 (for B1R and B2R), 1:4000 (for dynein, $\beta$-actin, IL-1 $\beta$, iNOS, VEGF, and CPM) and 1:3000 (nitrotyrosine). The nitration of protein tyrosine residues generating 3-nitrotyrosine has been used as a footprint for the formation of peroxynitrite in-vivo (Greenacre and Ischiropoulos, 2001).

\section{Immunofluorescence Staining}

At day 15, rats were anesthetized with sodium pentobarbital (60 mg. $\mathrm{kg}^{-1}$, i.p.) and then perfused with a paraformaldehyde solution (4\% PFA). Dissected retinae were then post-fixed in $4 \%$ PFA for $2 \mathrm{~h}$ and kept in $70 \%$ alcohol overnight at room temperature for a paraffin embedding. The retinae were then cut into $10-\mu \mathrm{m}$-thick sections and placed onto glass slides and kept at $4^{\circ} \mathrm{C}$ till the day of experiment. For proteins detection, the sections were deparaffinized prior to the immunofluorescence experiment. First, glass slides were

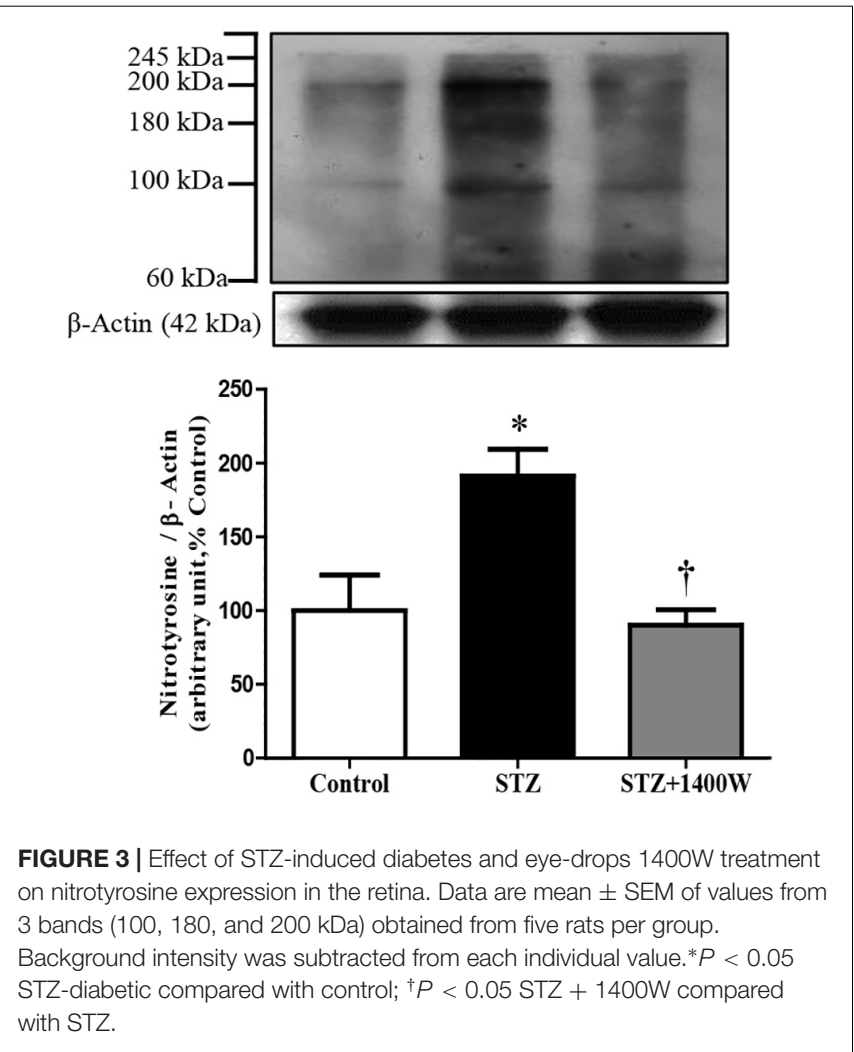

incubated in sodium citrate buffer at $95^{\circ} \mathrm{C}$ for $45 \mathrm{~min}$. Sections were then allowed to cool down for $20 \mathrm{~min}$. Sections were then washed 3 times ( 5 min each) with $0.1 \mathrm{M}$ PBS buffer ( $\mathrm{pH} 7.4$ ) and incubated for $1 \mathrm{~h}$ at room temperature in blocking buffer (PBS containing $10 \%$ donkey serum and $0.25 \%$ triton $\mathrm{X}-100$ ). Sections were left incubated overnight at room temperature with the blocking buffer containing primary antibodies: polyclonal rabbit antiserum to rat B1R (1:200), mouse monoclonal anti-iNOS
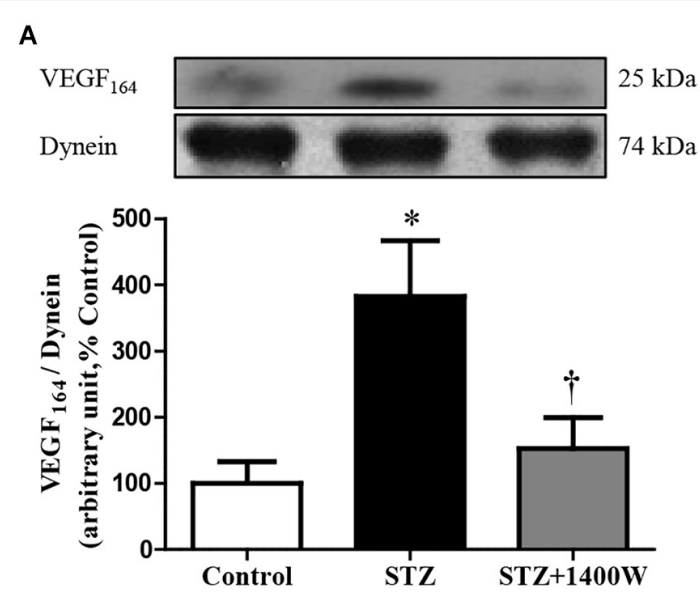

B

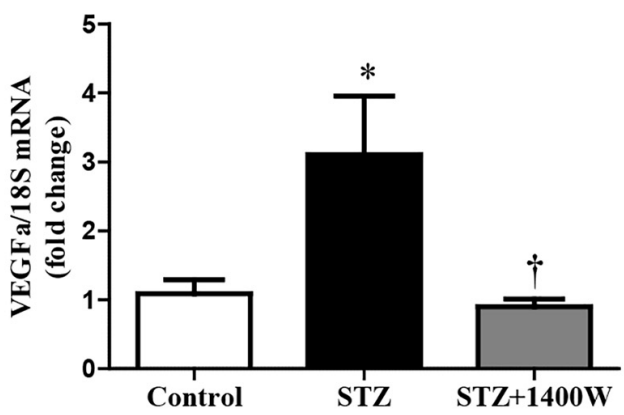

C

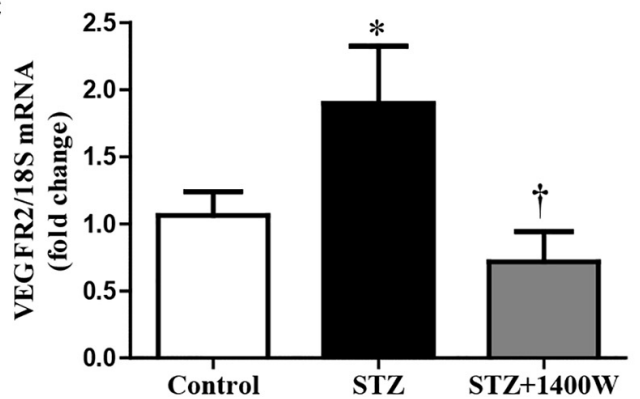

FIGURE 4 | Effect of STZ-induced diabetes and eye-drops 1400W treatment on protein expression of VEGF 164 (A), mRNA levels of VEGF-A (B), and VEGF-R2 (C) in the retina. Data are mean \pm SEM of values obtained from five to six rats in each group. ${ }^{*} P<0.05 \mathrm{STZ}$-diabetic compared with control. ${ }^{\dagger} P<0.05 \mathrm{STZ}+1400 \mathrm{~W}$ compared with STZ. 
(1:200, mouse, ab49999; Abcam, Cambridge, United States). The following day, slides were washed $3 \times 5 \mathrm{~min}$ in PBS $0.1 \mathrm{M}$ and then incubated for $2 \mathrm{~h}$ at room temperature with Alexa Fluor 488 donkey secondary anti-rabbit IgG (1:200, A21206, Invitrogen) to visualize B1R, with Alexa Fluor 555 donkey antimouse IgG (1:200, A31570, Invitrogen) to visualize iNOS. At the end, the slides were washed and mounted using glycerol solution. Images were obtained with a confocal microscope Zeiss-LSM800 equipped with an argon laser (Carl Zeiss, Jena, Germany) and transferred to a computer and analyzed using NIH ImageJ 1.36b Software (NIH, Bethesda, MD, United States). Images were obtained at $20 \mathrm{x}$ and $40 \mathrm{x}$ objective. Semi-quantification of immunofluorescence staining intensity was made on 5 randomly selected surface areas of each retina from four STZdiabetic rats, four controls and four STZ-diabetic treated rats. Background intensity (gray intensity) was subtracted from each individual value.

\section{Statistical Analysis}

Statistical analysis was performed using Prism ${ }^{\mathrm{TM}}$ version 5.0 (GraphPad Software Inc., La Jolla, CA, United States). Results are expressed as the mean \pm SEM and $n$ represents the number of rats used in each experiment. One-way ANOVA followed by Tukey's post hoc test was used for all the measurements. Results were considered significant at a value of $P<0.05$.

\section{RESULTS}

\section{Physiological Parameters}

At the time of sacrifice, blood glucose concentration was significantly higher in STZ-diabetic groups compared with control rats, but no statistical difference was seen between nontreated and treated STZ-diabetic rats with R-838 and/or 1400W (Table 2). Body weight of STZ-diabetic rats was significantly lower than the one of age-matched control rats. Administration of R-838 and/or 1400W had no effect on body weight in both control and STZ-diabetic rats (Table 2). Of note, no symptoms of ocular irritation (redness or corneal opacity) or the presence of porphyrin secretion around the eyes were seen during the whole period of treatment.

\section{Effect of iNOS Inhibition on Protein and mRNA Levels of Immunomodulators in Diabetic Retina}

An increase of iNOS expression was seen concomitantly with an elevated expression of B1R and CPM in STZ-diabetic retina. In comparison to control retina, iNOS expression was increased by six-fold at protein level, and by 2.5 -fold at mRNA level in diabetic retinae (Figures 1A,B). B1R expression was also increased by $\approx 3.5$-fold at protein level and 2.2 -fold at mRNA level in STZ-diabetic retina (Figures 2A,B). CPM protein expression was increased by $\approx$ six-fold in STZ-diabetic retina (Figure 2E). The increased expression of iNOS, B1R and CPM were reversed to control levels by the treatment with $1400 \mathrm{~W}$, providing evidence that iNOS inhibition reversed not only $\mathrm{B} 1 \mathrm{R}$ expression but also the biosynthesis of B1R agonists by CPM. This occurs without significant changes on B2R protein expression, yet $1400 \mathrm{~W}$ significantly increased B2R mRNA level in STZ-retina (Figures 2C,D).

Western blot analysis revealed that the intensity of several nitrosylated protein bands, notably at 200, 180 , and $100 \mathrm{kDa}$, increased in the retina of STZ-diabetic rats compared to control (Figure 3). The eye-drops application of $1400 \mathrm{~W}$ reversed the nitration reaction to control values, suggesting that iNOS is involved in protein nitration. This possibility is supported by the absence of nitrotyrosine residues in the retina of knockout iNOS mice in comparison with wild-type mice in a model of ischemic retina (Sennlaub et al., 2001).

VEGF-A plays a key role in increasing vascular permeability and promoting the angiogenesis in DR. Thus, intravitreal injections of anti-VEGF are one of the treatments used to stop DR progression. The protein expression of $\mathrm{VEGF}_{164}$, which is
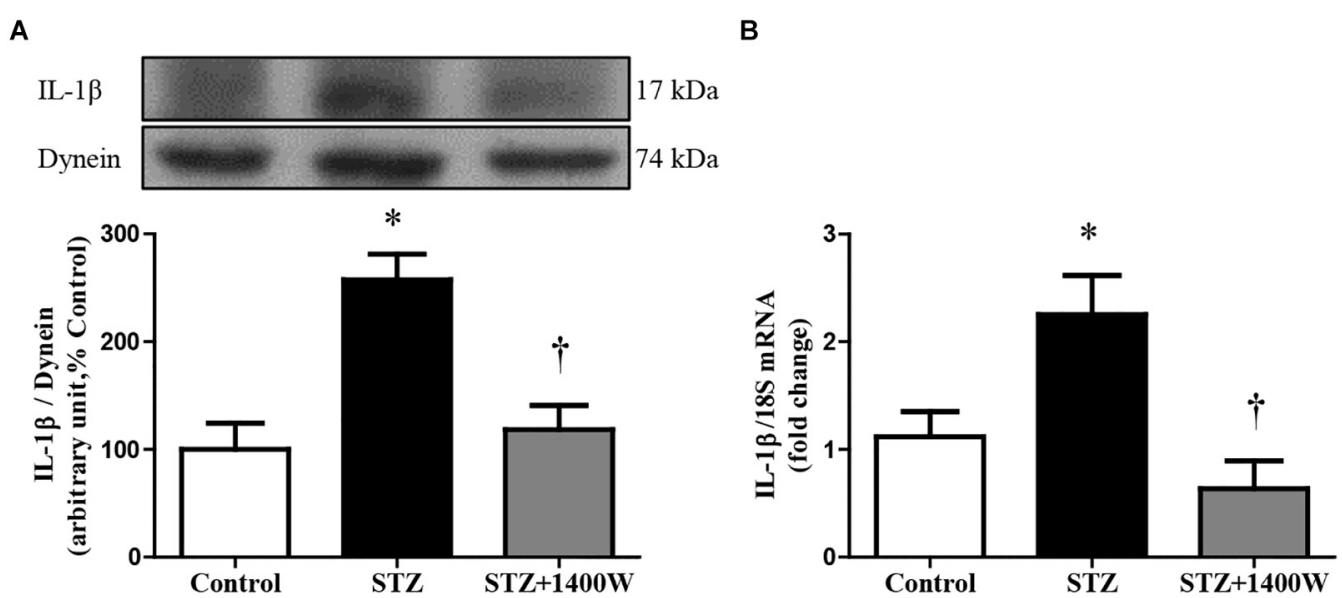

FIGURE 5 | Effect of STZ-induced diabetes and eye-drops 1400W treatment on protein (A) and mRNA (B) expression of IL-1 13 in the retina. Data are mean \pm SEM of values obtained from five rats in each group. ${ }^{*} P<0.05$ STZ-diabetic compared with control; ${ }^{\dagger} P<0.05 \mathrm{STZ}+1400 \mathrm{~W}$ compared with STZ. 


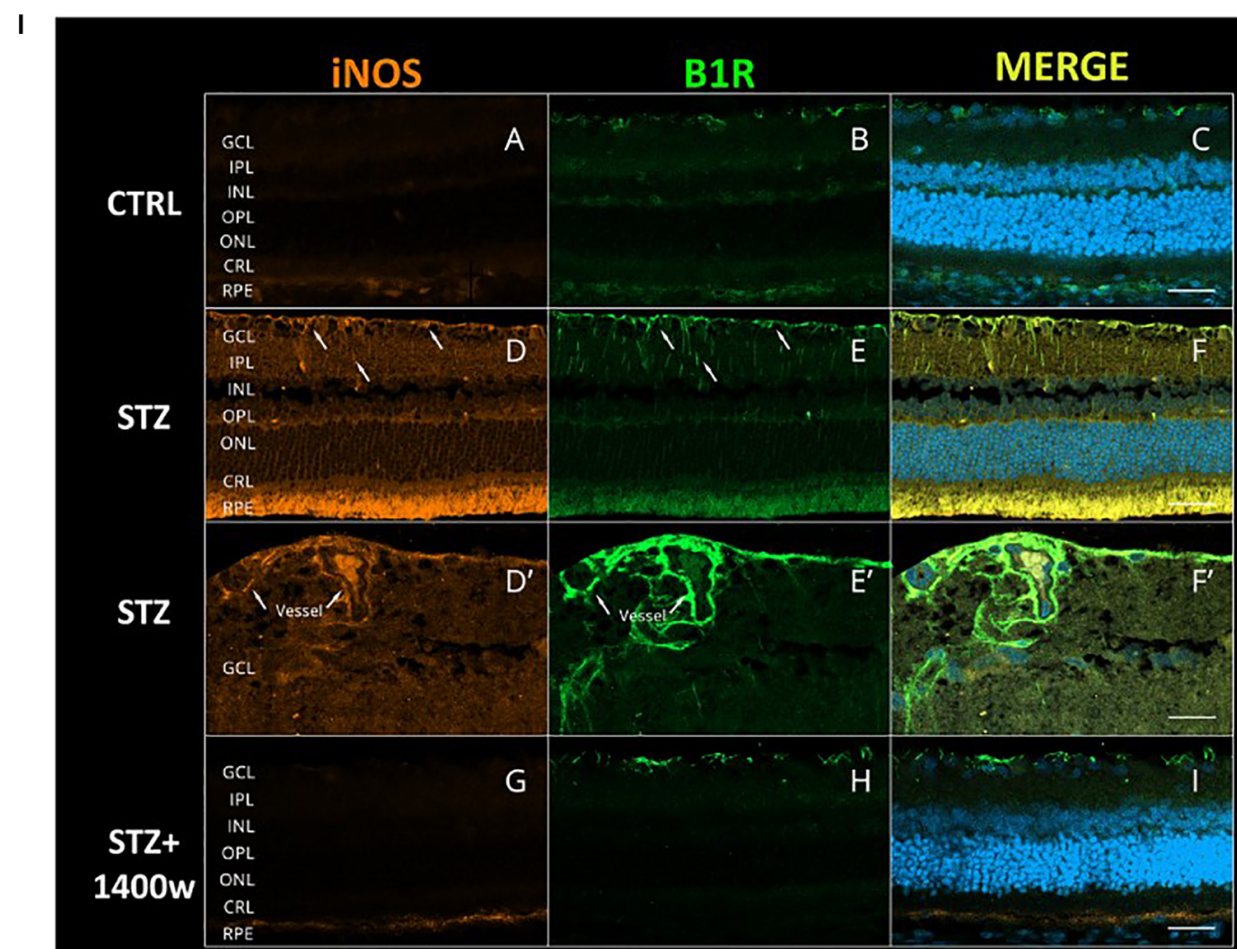

II
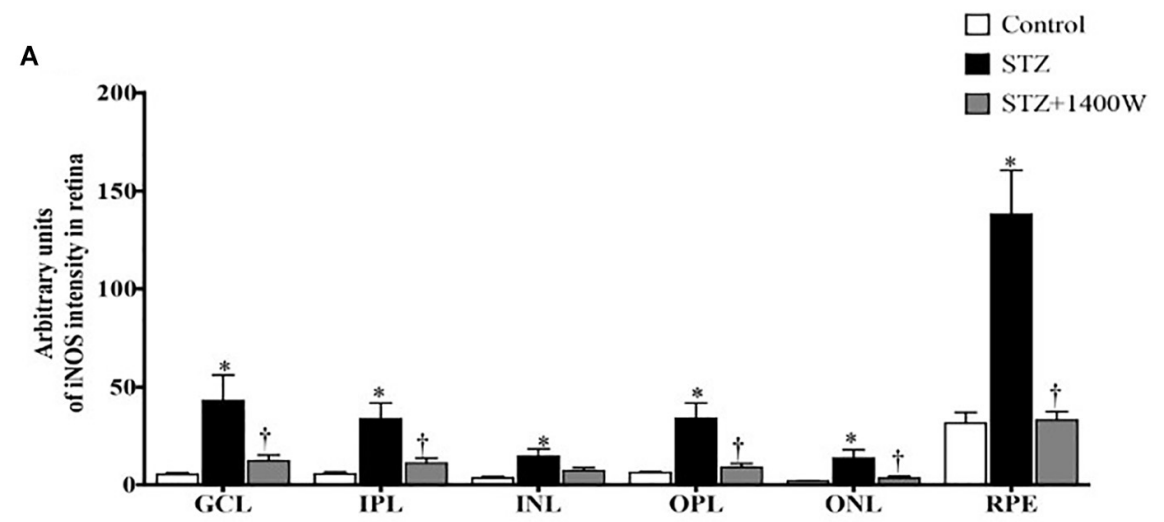

B

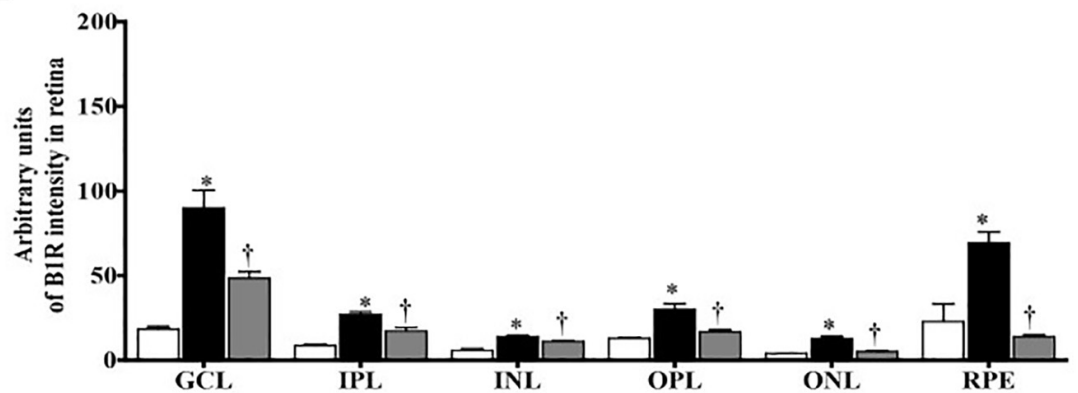

FIGURE 6 | (I) Microphotographs of immunolocalization of iNOS (orange, A,D,D', G) and B1R (green, B,E,E',H) in the retina of control (CTRL) and STZ-diabetic rats treated by eye-drops with vehicle or $1400 \mathrm{~W}$. Representative microphotographs of merge immunolabeling are shown (C,F,F',I). All sections were counter-stained for DAPI (blue, shown on merged images only), which labels cell nuclei. Arrows show the presence of iNOS and B1R in the same areas of GCL and IPL (D,E), notably on (Continued) 
FIGURE 6 | Continued

blood vessels (D',E'). Both proteins were colocalized in the STZ-retina (F,F') but not in control (C) or STZ-retina treated with 1400W (I). Images were obtained at $20 \times(\mathbf{A}-\mathbf{F}, \mathbf{G}-\mathbf{I})$ and 40× (D'-F') objective. Scale bar: $40 \mu \mathrm{m}$ (A-F,G-I) and $20 \mu \mathrm{m}$ ('D'-F'). CRL, cones and rods layer; GCL, ganglion cell layer; INL, inner nuclear layer; IPL, inner plexiform layer; ONL, outer nuclear layer; OPL, outer plexiform layer; RPE, retinal pigmented epithelium. (II) Quantification of the fluorescent intensity is depicted for iNOS (A) and B1R (B) in the different layers of the retina. Data are mean \pm SEM of values obtained from four rats per group and four sections per animal. ${ }^{*} P<0.05$ STZ-diabetic compared with control; ${ }^{\dagger} P<0.05$ STZ + 1400W compared with STZ.

one isoform of VEGF-A, was increased by four-fold while the mRNA level of VEGF-A was increased by 3-fold in diabetic retina (Figures 4A,B). The enhanced expression of VEGF-A was reversed by the 1-week treatment with 1400W. Likewise, VEGF-R2 expression was significantly increased at mRNA level in STZ-diabetic retina and normalized by treatment with $1400 \mathrm{~W}$ (Figure 4C). Similarly, the expression of IL-1 $\beta$ was increased by 2.5-fold at protein and mRNA levels in STZ-retina, and this was completely reversed by $1400 \mathrm{~W}$ treatment (Figures 5A,B). This cytokine is known to enhance the expression of B1R through NF$\kappa \mathrm{B}$. The mRNA expression of TNF- $\alpha$, another cytokine involved in the induction of B1R (Leeb-Lundberg et al., 2005), was also significantly enhanced in diabetic retina and normalized by the treatment with $1400 \mathrm{~W}$ (fold change of control: $1.0 \pm 0.2$; STZ: $4.7 \pm 0.9, P<0.05 ; \mathrm{STZ}+1400 \mathrm{~W}: 2.0 \pm 0.3, P<0.05, n=5)$.

\section{Effect of iNOS Inhibition on B1R and iNOS Immunoreactivity in the Diabetic Retina}

The immunofluorescence staining confirmed the enhanced levels of iNOS and B1R in the STZ-diabetic retina. In contrast, iNOS and B1R immunostaining was slightly detectable in control retina and no colocalization was evidenced (Figures 6I A-C). STZinduced diabetes increased strongly the expression of iNOS and B1R in all the retina layers (Figures 6I D,E). Both markers were mainly colocalized in the GCL, inner retina (INL and IPL) and the retinal pigmented layer (Figures 6I F). The latter forms the outer blood-retinal barrier. iNOS and B1R are also colocalized on blood vessels in the GCL (Figures 6I D'-F'). iNOS inhibition with 1400W decreased the high staining and colocalization of B1R and iNOS induced by diabetes (Figures 6I G-I), suggesting an implication of iNOS in the positive feedback regulation of B1R expression. Semi-quantitative values of iNOS and B1R intensity of immunofluorescence staining in control and STZdiabetic retina without and with $1400 \mathrm{~W}$ treatment are given in Figures 6II A,B.

\section{Effect of iNOS Inhibition and B1R Activation on Retinal Vascular Permeability}

Following the upregulation of $\mathrm{B} 1 \mathrm{R}$ and iNOS in the STZdiabetic retina, we determined whether B1R was functional and could interact with iNOS in an inflammatory response such as the breakage of blood-retinal barrier. The 1-week treatment with $1400 \mathrm{~W}$ reversed the STZ-induced increase in vascular permeability and reduced significantly the response to the B1R agonist in diabetic retina (Figure 7 ). The iNOS inhibitor had no impact in control rats treated with vehicle or R-838, which do not overexpress B1R. This provides evidence that iNOS activation mediates the B1R retinal vascular hyperpermeability in diabetes.

\section{DISCUSSION}

In the present study, we showed that iNOS plays an important role in the development of vascular damage linked to DR and in B1R-induced vascular permeability. We found that eye-drops application of the selective iNOS inhibitor, 1400W, reversed inflammatory response, nitrosative stress and vascular hyperpermeability in the retina of STZ-diabetic rats. Importantly, this study provides the first evidence that B1R is colocalized with iNOS throughout the retina and that B1R activates iNOS to enhance vascular permeability in this model of DR. A positive loop is suggested between iNOS and B1R to amplify and perpetuate the retinal inflammatory process. This is keeping with earlier data showing that B1R antagonism (Pouliot et al., 2012; Hachana et al., 2018) had similar beneficial effects than iNOS inhibition in this model of DR (Figure 8).

\section{iNOS Implication in Diabetic Retinopathy}

The increase of the oxidative stress is considered as an important factor in the pathophysiology of DR. Chronic hyperglycemia induces oxidative stress, which can consequently damage proteins, lipids, and DNA (Stadler, 2011). Retinal vascular oxidative stress persisted even after glucose level normalization (Ihnat et al., 2007). Increased retinal expression of iNOS is known to be a key factor responsible for diabetes-induced retinal inflammation (Abu El-Asrar et al., 2004; Kern, 2007). Our results

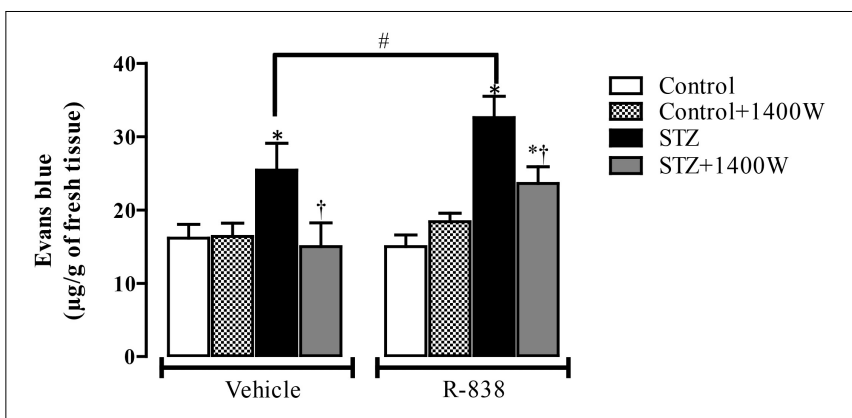

FIGURE 7 | Effect of STZ-induced diabetes, eye-drops treatment with $1400 \mathrm{~W}$ and intravitreal B1R agonist (R-838) on retinal vascular permeability. Data are mean \pm SEM obtained from 12 rats per group (vehicle) and 5 rats per group (R-838 and control $+1400 \mathrm{~W}) .{ }^{*} P<0.05$ STZ-diabetic compared with control; ${ }^{\dagger} P<0.05$ STZ $+1400 \mathrm{~W}$ compared with STZ; ${ }^{\#} P<0.05$ between STZ treated with vehicle and R-838. 


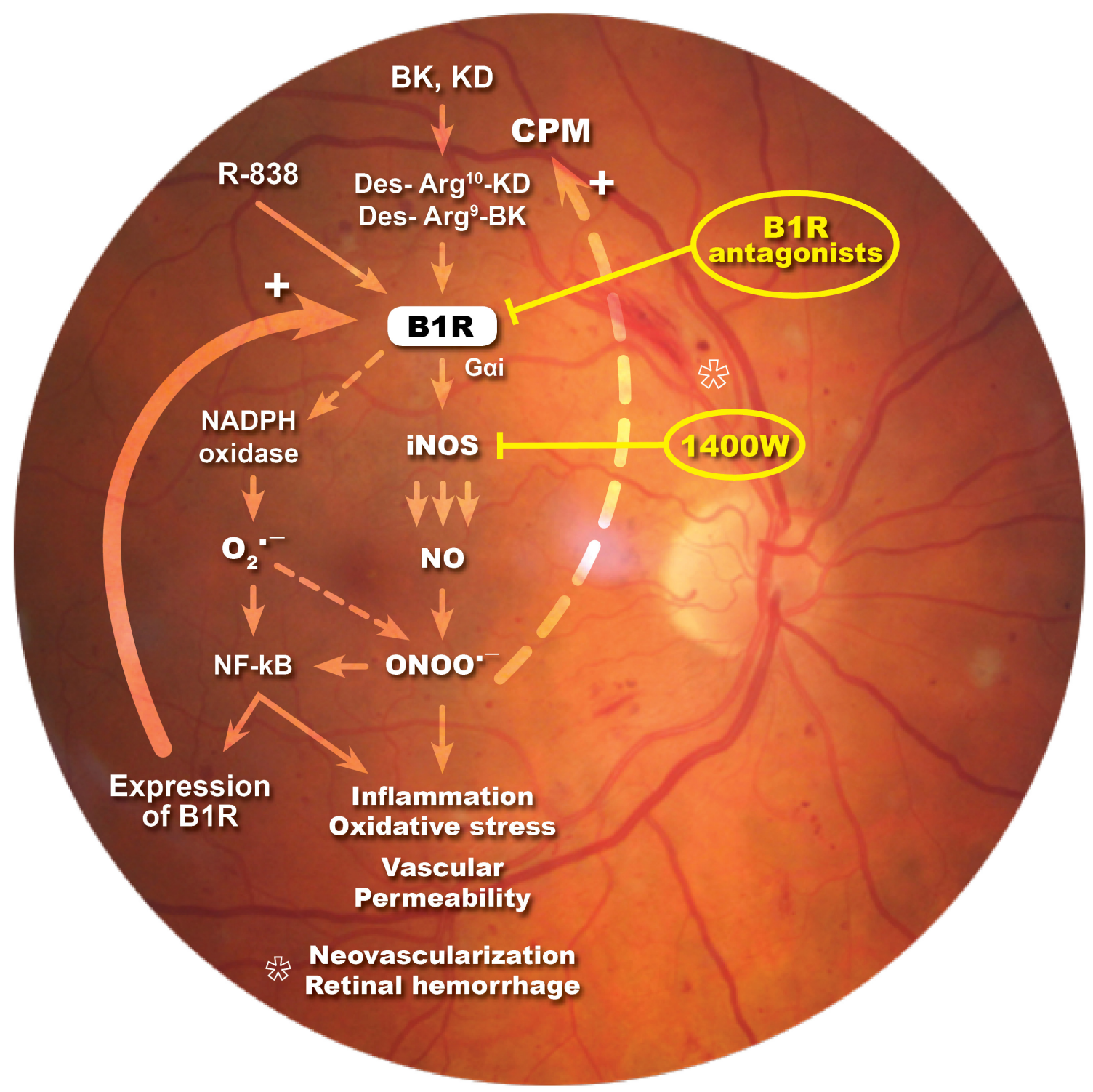

FIGURE 8 | Schematic diagram showing how B1R and iNOS can partake in a mutual auto-induction and amplification loop to enhance nitrogen species formation and inflammation in diabetic retina. B1R agonists enhance the formation of peroxynitrite $\left(\mathrm{ONOO}^{-}\right)$through the activation of iNOS and NADPH oxidase pathways. iNOS activation produces high amount of NO while NADPH oxidase activation leads to superoxide anion $\left(\mathrm{O}_{2}{ }^{-}{ }^{-}\right)$formation that can rapidly react with NO to form $\mathrm{ONOO}^{-}$. Peroxynitrite formation induces an inflammatory response, enhances the oxidative stress and vascular permeability, neovascularization and retinal hemorrhage. Both $\mathrm{O}_{2}{ }^{-}$and $\mathrm{ONOO}^{-}$are known to activate the transcriptional nuclear factor, $\mathrm{NF}-\mathrm{kB}$, which is involved in the transcription of several inflammatory genes, notably iNOS, B1R, and CPM. iNOS inhibitor (1400W) and B1R antagonists prevent this vicious cycle and the pro-inflammatory effect of B1R.

with $1400 \mathrm{~W}$ are in agreement with the implication of iNOS through the oxidative stress in the onset of DR (Rosales et al., 2010; Silva et al., 2010).

Unlike the constitutive NOS, iNOS is activated under hypoxic and inflammatory conditions leading thus to excessive amounts of NO, which might contribute to the pathogenesis of DR (Abu El-Asrar et al., 2001; Rosales et al., 2010; Silva et al., 2010). Therefore, our approach was to selectively block iNOS, and leave intact nNOS and eNOS which play important physiological functions such as vasodilation and blood flow regulation. NO synthesized from iNOS promotes peroxynitrite formation, which is implicated in retinal endothelial and neuronal cell death, retinal neurodegeneration, and blood-retinal barrier breakdown in models of experimental diabetes (El-Remessy et al., 2003; el-Remessy et al., 2005; Zheng et al., 2007; Ali et al., 2008). In addition, peroxynitrite and the oxidative stress can activate the transcriptional nuclear factor NF- $\mathrm{kB}$, which is known to increase the transcription of several inflammatory cytokines such as IL- $1 \beta$ and TNF- $\alpha$, iNOS, and B1R (Leeb-Lundberg et al., 2005; Pall, 2013). Here, we found that elevated expression of iNOS associated with diabetes is accompanied by an elevated expression of nitrosylated proteins that is reversed by iNOS inhibition. 
This agrees with diabetic mice lacking iNOS which are protected from the diabetes-induced nitration of retinal proteins (Zheng et al., 2007). Consistently, nitrotyrosine immunolabeling was reported in the inner retina and retinal vasculature of diabetic rats (Du et al., 2002; Liu et al., 2013) and in diabetic human retina (Abu El-Asrar et al., 2004).

In a model of type 2 diabetes, iNOS was found expressed in the GCL, the INL, and at the ONL (Carmo et al., 2000). Also, a cytoplasm-associated immunoreactivity of iNOS was seen in ganglion cells, INL, glial cells, and vessels of diabetic human retinae (Abu El-Asrar et al., 2004). Recently, we reported B1R expression in retinal ganglion cells, INL, and Müller cells in STZ-diabetic retina (Hachana et al., 2018). In the present study, we show an increased expression of $\mathrm{B} 1 \mathrm{R}$ in diabetic retina accompanied by an increased expression of iNOS in the same regions. B1R and iNOS immunoreactivities were colocalized in the GCL, on blood vessels, the INL, and RPE. This colocalization may suggest interaction between both proteins.

\section{B1R Implication in Diabetic Retinopathy}

We have previously shown that B1R is implicated in the very early stage of DR (Abdouh et al., 2003, 2008; Pouliot et al., 2011, 2012; Hachana et al., 2018) and that B1R exerts potent effects on retinal vascular hyperpermeability. Herein we show again an increased retinal B1R expression at 2 weeks of diabetes. We found that the impact of B1R on retinal vascular permeability in diabetic rats is stronger when $\mathrm{B} 1 \mathrm{R}$ is stimulated by its agonist (R-838). It has been previously shown that B1R activates NADPH oxidase leading to increased production of superoxide anion in STZ-diabetic vessels through PKC $\beta 1 / 2$ (Haddad and Couture, 2017). Importantly, B1R enhanced iNOS expression in diabetic pancreas, adipose tissue, vessels and retina (Dias and Couture, 2012a,b; Pouliot et al., 2012; Tidjane et al., 2016), which is keeping with the activation of iNOS by B1R through Gai/ERK/MAPK signaling (Brovkovych et al., 2011). Hence the interaction between $\mathrm{B} 1 \mathrm{R}$, iNOS and NADPH oxidase represents a reasonable mechanism for the generation of nitrosylated proteins (Figure 3) through peroxynitrite formation. The latter is the result of a combination of NO (produced by iNOS) and superoxide anion derived from NADPH oxidase (Figure 8). This is expected to amplify the pro-inflammatory effects and expression of B1R and iNOS through a positive feedback loop as shown in other tissues of diabetic rats (Haddad and Couture, 2016). It seems that peroxynitrite can also exert a positive feedback loop to enhance the expression of CPM, yielding endogenous agonists to activate $\mathrm{B} 1 \mathrm{R}$. These results are in line with our previous study where we showed that enhanced iNOS expression in different organs of STZ-diabetic rats increases CPM expression through peroxynitrite formation (Haddad and Couture, 2016). Collectively, the present data suggest a strong

\section{REFERENCES}

Abdouh, M., Khanjari, A., Abdelazziz, N., Ongali, B., Couture, R., and Hassessian, H. M. (2003). Early upregulation of kinin B1 receptors in retinal microvessels of the streptozotocin-diabetic rat. Br. J. Pharmacol. 140, 33-40. doi: 10.1038/sj. bjp. 0705210 interaction between B1R and iNOS, which is further supported by the immunofluorescence study highlighting strong co-expression of iNOS and B1R.

\section{CONCLUSION}

This study shows that iNOS and B1R play a critical role in the early stage of DR. B1R and iNOS appear to partake in a mutual auto-induction and amplification loop to enhance nitrogen species formation and inflammation in diabetic retina. Hence, targeting the B1R-iNOS axis can represent a promising and non-invasive therapeutic approach in DR. However, further studies are needed to confirm the concentration and any potential side effect of $1400 \mathrm{~W}$ reaching to the retinal, corneal and choroidal compartments.

\section{DATA AVAILABILITY}

The datasets generated for this study are available on request to the corresponding author.

\section{AUTHOR CONTRIBUTIONS}

RO, EV, and RC conceived and designed the experiments. RO performed the experiments, analyzed the data, and drafted the manuscript. RC and EV supervised the study, edited, and wrote the final version of the manuscript. All authors approved the final manuscript.

\section{FUNDING}

This work was supported by Grants from the Canadian Institutes of Health Research (MOP-125962) and the FRQS Vision Health Research Network to EV and RC. RO received a Ph.D. Studentship Award from the Graduate Program of Physiology and an International Students' Scholarship from the Faculty of Graduate Studies, Université de Montréal.

\section{ACKNOWLEDGMENTS}

The authors greatly appreciate the technical assistance of Jacques Sénécal for the study in immunofluorescence. The authors thank the Department of Pharmacology and Physiology, Université de Montréal for giving access to the confocal microscope Zeiss-LSM800.

Abdouh, M., Talbot, S., Couture, R., and Hassessian, H. M. (2008). Retinal plasma extravasation in streptozotocin-diabetic rats mediated by kinin $\mathrm{B}(1)$ and $\mathrm{B}(2)$ receptors. Br. J. Pharmacol. 154, 136-143. doi: 10.1038/bjp.2008.48

Abu El-Asrar, A. M., Desmet, S., Meersschaert, A., Dralands, L., Missotten, L., and Geboes, K. (2001). Expression of the inducible isoform of nitric oxide synthase in the retinas of human subjects with diabetes 
mellitus. Am. J. Ophthalmol. 132, 551-556. doi: 10.1016/S0002-9394(01) 01127-8

Abu El-Asrar, A. M., Meersschaert, A., Dralands, L., Missotten, L., and Geboes, K. (2004). Inducible nitric oxide synthase and vascular endothelial growth factor are colocalized in the retinas of human subjects with diabetes. Eye 18, 306-313. doi: $10.1038 /$ sj.eye.6700642

Ali, T. K., Matragoon, S., Pillai, B. A., Liou, G. I., and El-Remessy, A. B. (2008). Peroxynitrite mediates retinal neurodegeneration by inhibiting nerve growth factor survival signaling in experimental and human diabetes. Diabetes 57, 889-898. doi: 10.2337/db07-1669

Bhat, M., Pouliot, M., Couture, R., and Vaucher, E. (2014). The kallikrein-kinin system in diabetic retinopathy. Prog. Drug Res. 69, 111-143. doi: 10.1007/9783-319-06683-7_5

Brovkovych, V., Zhang, Y., Brovkovych, S., Minshall, R. D., and Skidgel, R. A. (2011). A novel pathway for receptor-mediated post-translational activation of inducible nitric oxide synthase. J. Cell. Mol. Med. 15, 258-269. doi: 10.1111/j. 1582-4934.2009.00992.x

Carmo, A., Cunha-Vaz, J. G., Carvalho, A. P., and Lopes, M. C. (2000). Nitric oxide synthase activity in retinas from non-insulin-dependent diabetic GotoKakizaki rats: correlation with blood-retinal barrier permeability. Nitric Oxide 4, 590-596. doi: 10.1006/niox.2000.0312

Catanzaro, O. L., Capponi, J. A., Di Martino, I., Labal, E. S., and Sirois, P. (2017). Oxidative stress in the optic nerve and cortical visual area of steptozotocininduced diabetic wistar rats: blockade with a selective bradykinin B1 receptor antagonist. Neuropeptides 66, 97-102. doi: 10.1016/j.npep.2017.10.003

Cheung, N., Mitchell, P., and Wong, T. Y. (2010). Diabetic retinopathy. Lancet 376, 124-136. doi: 10.1016/S0140-6736(09)62124-3

Christopherson, K. S., and Bredt, D. S. (1997). Nitric oxide in excitable tissues: physiological roles and disease. J. Clin. Invest. 100, 2424-2429. doi: 10.1172/ JCI119783

Corbett, J. A., Tilton, R. G., Chang, K., Hasan, K. S., Ido, Y., Wang, J. L., et al. (1992). Aminoguanidine, a novel inhibitor of nitric oxide formation, prevents diabetic vascular dysfunction. Diabetes 41, 552-556. doi: 10.2337/diab.41.4.552

Couture, R., Blaes, N., and Girolami, J. P. (2014). Kinin receptors in vascular biology and pathology. Curr. Vasc. Pharmacol. 12, 223-248. doi: 10.2174/ 1570161112666140226121627

Couture, R., Harrisson, M., Vianna, R. M., and Cloutier, F. (2001). Kinin receptors in pain and inflammation. Eur. J. Pharmacol. 429, 161-176. doi: 10.1016/S00142999(01)01318-8

Dias, J. P., and Couture, R. (2012a). Blockade of kinin B(1) receptor reverses plasma fatty acids composition changes and body and tissue fat gain in a rat model of insulin resistance. Diabetes Obes. Metab. 14, 244-253. doi: 10.1111/j.1463-1326. 2011.01521.x

Dias, J. P., and Couture, R. (2012b). Suppression of vascular inflammation by kinin $\mathrm{B} 1$ receptor antagonism in a rat model of insulin resistance. J. Cardiovasc. Pharmacol. 60, 61-69. doi: 10.1097/FJC.0b013e3182576277

Dias, J. P., Talbot, S., Senecal, J., Carayon, P., and Couture, R. (2010). Kinin B1 receptor enhances the oxidative stress in a rat model of insulin resistance: outcome in hypertension, allodynia and metabolic complications. PLoS One 5:e12622. doi: 10.1371/journal.pone.0012622

Du, Y., Sarthy, V. P., and Kern, T. S. (2004). Interaction between NO and COX pathways in retinal cells exposed to elevated glucose and retina of diabetic rats. Am. J. Physiol. Regul. Integr. Comp. Physiol. 287, R735-R741. doi: 10.1152/ ajpregu.00080.2003

Du, Y., Smith, M. A., Miller, C. M., and Kern, T. S. (2002). Diabetes-induced nitrative stress in the retina, and correction by aminoguanidine. J. Neurochem. 80, 771-779. doi: 10.1046/j.0022-3042.2001.00737.x

Ellis, E. A., Guberski, D. L., Hutson, B., and Grant, M. B. (2002). Time course of NADH oxidase, inducible nitric oxide synthase and peroxynitrite in diabetic retinopathy in the BBZ/WOR rat. Nitric Oxide 6, 295-304. doi: 10.1006/niox. 2001.0419

el-Remessy, A. B., Bartoli, M., Platt, D. H., Fulton, D., and Caldwell, R. B. (2005). Oxidative stress inactivates VEGF survival signaling in retinal endothelial cells via PI 3-kinase tyrosine nitration. J. Cell Sci. 118, 243-252. doi: 10.1242/jcs. 01612

El-Remessy, A. B., Behzadian, M. A., Abou-Mohamed, G., Franklin, T., Caldwell, R. W., and Caldwell, R. B. (2003). Experimental diabetes causes breakdown of the blood-retina barrier by a mechanism involving tyrosine nitration and increases in expression of vascular endothelial growth factor and urokinase plasminogen activator receptor. Am. J. Pathol. 162, 1995-2004. doi: 10.1016/ S0002-9440(10)64332-5

Feener, E. P. (2010). Plasma kallikrein and diabetic macular edema. Curr. Diab. Rep. 10, 270-275. doi: 10.1007/s11892-010-0127-1

Fong, D. S., Aiello, L. P., Ferris, F. L. III, and Klein, R. (2004). Diabetic retinopathy. Diabetes Care 27, 2540-2553. doi: 10.2337/diacare.27.10.2540

Garvey, E. P., Oplinger, J. A., Furfine, E. S., Kiff, R. J., Laszlo, F., Whittle, B. J., et al. (1997). 1400W is a slow, tight binding, and highly selective inhibitor of inducible nitric-oxide synthase in vitro and in vivo. J. Biol. Chem. 272, 4959-4963. doi: 10.1074/jbc.272.8.4959

Goureau, O., Regnier-Ricard, F., and Courtois, Y. (1999). Requirement for nitric oxide in retinal neuronal cell death induced by activated muller glial cells. J. Neurochem. 72, 2506-2515. doi: 10.1046/j.1471-4159.1999.0722506.x

Greenacre, S. A., and Ischiropoulos, H. (2001). Tyrosine nitration: localisation, quantification, consequences for protein function and signal transduction. Free Radic. Res. 34, 541-581. doi: 10.1080/10715760100300471

Hachana, S., Bhat, M., Senecal, J., Huppe-Gourgues, F., Couture, R., and Vaucher, E. (2018). Expression, distribution and function of kinin B1 receptor in the rat diabetic retina. Br. J. Pharmacol. 175, 968-983. doi: 10.1111/bph.14138

Haddad, Y., and Couture, R. (2016). Interplay between the kinin B1 receptor and inducible nitric oxide synthase in insulin resistance. Br. J. Pharmacol. 173, 1988-2000. doi: 10.1111/bph.13491

Haddad, Y., and Couture, R. (2017). Localization and interaction between kinin B1 receptor and NADPH oxidase in the vascular system of diabetic rats. Front. Physiol. 8:861. doi: 10.3389/fphys.2017.00861

Hao, L. N., Wang, M., Ma, J. L., and Yang, T. (2012). Puerarin decreases apoptosis of retinal pigment epithelial cells in diabetic rats by reducing peroxynitrite level and iNOS expression. Sheng Li Xue Bao 64, 199-206.

Hoeben, A., Landuyt, B., Highley, M. S., Wildiers, H., Van Oosterom, A. T., and De Bruijn, E. A. (2004). Vascular endothelial growth factor and angiogenesis. Pharmacol. Rev. 56, 549-580. doi: 10.1124/pr.56.4.3

Ihnat, M. A., Thorpe, J. E., Kamat, C. D., Szabo, C., Green, D. E., Warnke, L. A., et al. (2007). Reactive oxygen species mediate a cellular 'memory' of high glucose stress signalling. Diabetologia 50, 1523-1531. doi: 10.1007/s00125-0070684-2

Kern, T. S. (2007). Contributions of inflammatory processes to the development of the early stages of diabetic retinopathy. Exp. Diabetes Res. 2007:95103. doi: $10.1155 / 2007 / 95103$

Kern, T. S., and Engerman, R. L. (2001). Pharmacological inhibition of diabetic retinopathy: aminoguanidine and aspirin. Diabetes 50, 1636-1642. doi: 10.2337/ diabetes.50.7.1636

Kilkenny, C., Browne, W., Cuthill, I. C., Emerson, M., Altman, D. G., and NC3Rs Reporting Guidelines Working Group. (2010). Animal research: reporting in vivo experiments: the ARRIVE guidelines. Br. J. Pharmacol. 160, 1577-1579. doi: 10.1111/j.1476-5381.2010.00872.x

Korhonen, R., Lahti, A., Kankaanranta, H., and Moilanen, E. (2005). Nitric oxide production and signaling in inflammation. Curr. Drug Targets Inflamm. Allergy 4, 471-479. doi: 10.2174/1568010054526359

Lacoste, B., Tong, X. K., Lahjouji, K., Couture, R., and Hamel, E. (2013). Cognitive and cerebrovascular improvements following kinin $\mathrm{B} 1$ receptor blockade in $\mathrm{Al}$ zheimer's disease mice. J. Neuroinflamm. 10:57. doi: 10.1186/1742-2094-10-57

Leeb-Lundberg, L. M., Marceau, F., Muller-Esterl, W., Pettibone, D. J., and Zuraw, B. L. (2005). International union of pharmacology. XLV. Classification of the kinin receptor family: from molecular mechanisms to pathophysiological consequences. Pharmacol. Rev. 57, 27-77. doi: 10.1124/pr.57.1.2

Liu, Q., Li, J., Cheng, R., Chen, Y., Lee, K., Hu, Y., et al. (2013). Nitrosative stress plays an important role in Wnt pathway activation in diabetic retinopathy. Antioxid. Redox Signal. 18, 1141-1153. doi: 10.1089/ars.2012.4583

McGrath, J. C., and Lilley, E. (2015). Implementing guidelines on reporting research using animals (ARRIVE etc.): new requirements for publication in BJP. Br. J. Pharmacol. 172, 3189-3193. doi: 10.1111/bph.12955

Mishra, A., and Newman, E. A. (2010). Inhibition of inducible nitric oxide synthase reverses the loss of functional hyperemia in diabetic retinopathy. Glia 58, 1996-2004. doi: 10.1002/glia.21068

Pall, M. L. (2013). The NO/ONOO-cycle as the central cause of heart failure. Int. J. Mol. Sci. 14, 22274-22330. doi: 10.3390/ijms141122274

Pouliot, M., Hetu, S., Lahjouji, K., Couture, R., and Vaucher, E. (2011). Modulation of retinal blood flow by kinin B(1) receptor in Streptozotocin-diabetic rats. Exp. Eye Res. 92, 482-489. doi: 10.1016/j.exer.2011.03.007 
Pouliot, M., Talbot, S., Senecal, J., Dotigny, F., Vaucher, E., and Couture, R. (2012). Ocular application of the kinin B1 receptor antagonist LF22-0542 inhibits retinal inflammation and oxidative stress in streptozotocin-diabetic rats. PLoS One 7:e33864. doi: 10.1371/journal.pone.0033864

Regoli, D., and Barabe, J. (1980). Pharmacology of bradykinin and related kinins. Pharmacol. Rev. 32, 1-46.

Regoli, D., Nsa Allogho, S., Rizzi, A., and Gobeil, F. J. (1998). Bradykinin receptors and their antagonists. Eur. J. Pharmacol. 348, 1-10. doi: 10.1016/ S0014-2999(98)00165-4

Ricciardolo, F. L., Nijkamp, F. P., and Folkerts, G. (2006). Nitric oxide synthase (NOS) as therapeutic target for asthma and chronic obstructive pulmonary disease. Curr. Drug Targets 7, 721-735. doi: 10.2174/138945006777435290

Rosales, M. A., Silva, K. C., Lopes de Faria, J. B., and Lopes de Faria, J. M. (2010). Exogenous SOD mimetic tempol ameliorates the early retinal changes reestablishing the redox status in diabetic hypertensive rats. Invest. Ophthalmol. Vis. Sci. 51, 4327-4336. doi: 10.1167/iovs.09-4690

Sennlaub, F., Courtois, Y., and Goureau, O. (2001). Inducible nitric oxide synthase mediates the change from retinal to vitreal neovascularization in ischemic retinopathy. J. Clin. Invest. 107, 717-725. doi: 10.1172/JCI10874

Sennlaub, F., Courtois, Y., and Goureau, O. (2002). Inducible nitric oxide synthase mediates retinal apoptosis in ischemic proliferative retinopathy. J. Neurosci. 22, 3987-3993. doi: 10.1523/JNEUROSCI.22-10-03987.2002

Silva, K. C., Rosales, M. A., de Faria, J. B., and de Faria, J. M. (2010). Reduction of inducible nitric oxide synthase via angiotensin receptor blocker prevents the oxidative retinal damage in diabetic hypertensive rats. Curr. Eye Res. 35, 519-528. doi: 10.3109/02713681003664923

Stadler, K. (2011). Peroxynitrite-driven mechanisms in diabetes and insulin resistance - the latest advances. Curr. Med. Chem. 18, 280-290. doi: 10.2174/ 092986711794088317
Tidjane, N., Gaboury, L., and Couture, R. (2016). Cellular localisation of the kinin $\mathrm{B} 1 \mathrm{R}$ in the pancreas of streptozotocin-treated rat and the anti-diabetic effect of the antagonist SSR240612. Biol. Chem. 397, 323-336. doi: 10.1515/hsz-20150230

Toda, N., and Nakanishi-Toda, M. (2007). Nitric oxide: ocular blood flow, glaucoma, and diabetic retinopathy. Prog. Retin. Eye Res. 26, 205-238. doi: 10.1016/j.preteyeres.2007.01.004

Wilkinson-Berka, J. L., and Fletcher, E. L. (2004). Angiotensin and bradykinin: targets for the treatment of vascular and neuro-glial pathology in diabetic retinopathy. Curr. Pharm. Des. 10, 3313-3330. doi: 10.2174/138161204338 3179

Yuasa, I., Ma, N., Matsubara, H., Fukui, Y., and Uji, Y. (2008). Inducible nitric oxide synthase mediates retinal DNA damage in Goto-Kakizaki rat retina. Jpn. J. Ophthalmol. 52, 314-322. doi: 10.1007/s10384-008-0542-x

Zheng, L., Du, Y., Miller, C., Gubitosi-Klug, R. A., Kern, T. S., Ball, S., et al. (2007). Critical role of inducible nitric oxide synthase in degeneration of retinal capillaries in mice with streptozotocin-induced diabetes. Diabetologia 50, 1987-1996. doi: 10.1007/s00125-007-0734-9

Conflict of Interest Statement: The authors declare that the research was conducted in the absence of any commercial or financial relationships that could be construed as a potential conflict of interest.

Copyright (C) 2019 Othman, Vaucher and Couture. This is an open-access article distributed under the terms of the Creative Commons Attribution License (CC BY). The use, distribution or reproduction in other forums is permitted, provided the original author(s) and the copyright owner(s) are credited and that the original publication in this journal is cited, in accordance with accepted academic practice. No use, distribution or reproduction is permitted which does not comply with these terms. 